\title{
One-Pot Synthesis of Sustainable High-Performance Thermoset by Exploiting Eugenol Functionalized 1,3-Dioxolan-4-one
}

\author{
Stefano Gazzotti, ${ }^{\dagger, \ddagger \S}$ Minna Hakkarainen, ${ }^{*},{ }^{\ddagger}$ Karin H. Adolfsson, ${ }^{\ddagger}$ Marco Aldo Ortenzi, ${ }^{\dagger, \S}$ \\ Hermes Farina, ${ }^{\dagger, \S}$ Giordano Lesma, ${ }^{\dagger, \S}$ and Alessandra Silvani ${ }^{\dagger, \S(}$ \\ ${ }^{\dagger}$ Department of Chemistry, Università degli Studi di Milano, Via Golgi 19, 20133 Milan, Italy \\ ${ }^{\ddagger}$ Department of Fibre and Polymer Technology, KTH Royal Institute of Technology, Teknikringen 56, 10044 Stockholm, Sweden \\ ${ }^{\S}$ CRC Materiali Polimerici “LaMPO”, Department of Chemistry, Università degli Studi di Milano, Via Golgi 19, 20133 Milan, Italy
}

Supporting Information

\begin{abstract}
Dioxolan-4-one (DOX) chemistry was explored for production of "one-pot" biobased polyester thermosets. DOX monomer was first functionalized by naturally occurring eugenol to introduce a structural element, which could induce cross-linking reaction through cationic polymerization of the double bond. The feasibility of polymerizing DOX monomers bearing bulky side groups was proven by model phenol-substituted DOX monomer (PhDOX). Once the reaction was shown to be effective, the same protocol was applied to eugenol-substituted monomer (EuDOX). A brief screening of the optimal catalyst concentration was performed, to obtain a highly cross-linked product. The synthesized thermoset showed good thermal resistance and high mechanical strength probably due to the rich aromatic content. The obtained thermoset was further subjected to microwave-assisted hydrothermal degradation test, which demonstrated complete recyclability to water or methanol soluble products. NMR and matrix-assisted laser desorption/ ionization-mass spectroscopy analyses of the obtained degradation products unveiled the structure of the thermoset, strongly indicating that the polymerization of eugenol-functionalized DOX monomer resulted in polylactide-like chains connected with aromatic-aliphatic segments resulting from the reaction of the eugenol double bonds. The presence of free hydroxyl and carboxyl groups sheds light on the mechanism behind the observed shape-memory and self-healing properties.
\end{abstract}

KEYWORDS: DOX, Biobased, Thermoset, PLA, Eugenol

\section{INTRODUCTION}

Thermoset resins have been widely used in many different fields of application, ranging from coatings to adhesives, electronics, and many others. Considering their wide applicability and high industrial value, research efforts have targeted the development of novel biobased ${ }^{1-6}$ and recyclable $^{7-9}$ thermosets with the aim to replace the mostly used petroleum-based and not easily recyclable counterparts. A thermoset resin able to conjugate both these features (i.e., renewability and recyclability) can be considered as the best target possible from a sustainability point of view. The preparation of polylactic acid (PLA)-based thermosets appears as a suitable strategy to achieve this result, ${ }^{10-13}$ taking into account that PLA is a well-known biobased, biodegradable, and biocompatible polyester. ${ }^{14,15}$ However, its use as thermosetting resin is currently accomplished only through postmodification reactions. ${ }^{16-19}$ In addition the properties and mechanical strength are not good enough for many thermoset applications.

Compared to the multistep approach, the use of tailor-made monomers that enable one-pot PLA-like thermoset syntheses appears valuable from an industrial point of view, reducing the synthetic steps needed for obtaining the final product. To this regard, however, the reduced monomer scope in classical PLA synthetic methodologies (i.e., ring opening polymerization and polycondensation) stands as a major limitation. The use of recently described O-carboxyanhydrides (OCAs) ${ }^{20,21}$ and 1,3dioxolan-4-ones (DOXs) ${ }^{22}$ monomers can significantly broaden the functionalization possibilities toward highly substituted PLA-based materials. In particular, while OCAs synthesis relies on highly toxic reagents and results into highly unstable products, DOX monomers can be prepared starting from safer precursors and stored for long periods of time. ${ }^{23}$ The straightforward synthesis of DOX monomers also allows the easy introduction of a wide range of side groups, which can be exploited for the fine-tuning of the material's final properties.

Received: July 27, 2018

Revised: September 27, 2018

Published: October 3, 2018 
Within this context, a eugenol-derived side group could be a valuable option providing additional functionality as well as renewability. Eugenol can be extracted from clove oil and lignin and it is very well-known for its antifungal and antimicrobial properties. ${ }^{24}$ In addition, the copresence of a phenol moiety together with an allyl group makes it attractive from a chemical point of view, opening the possibility for many different synthetic approaches and improvement of materials properties such as mechanical strength. ${ }^{25}$ To this regard, several examples have been reported in literature showing the use of eugenol as a building block for the preparation of different kinds of high performances thermosets with, for example, great heat resistance, low permittivity, and low flammability. ${ }^{26-28}$

Following our interest in DOXs polymerization chemistry, we aimed to synthesize a novel eugenol-bearing 1,3-dioxolan-4one monomer, and to utilize it for one-pot preparation of a high performing thermoset. It was hypothesized that this monomer could react or polymerize through two mechanisms resulting in polylactide-like chains connected with aromaticaliphatic hydrocarbon segments formed by reaction of the eugenol double bonds. The aromatic group of the eugenol unit is also expected to enhance the mechanical properties of the resulting thermoset as compared to previous fully aliphatic polylactide-based thermosets. Addressing the concept of circular chemistry and manufacturing, we also evaluated the possibility to recycle the obtained thermoset back to functional intermediates through a microwave-assisted hydrothermal reaction.

\section{EXPERIMENTAL SECTION}

Chemicals and Materials. All reagents were purchased by SigmaAldrich and used as received. ( \pm )-3-Chloro-1,2-propanediol, 98\%; $\mathrm{HNO}_{3}, \geq 65 \%$; eugenol, $\geq 98 \%$; $\mathrm{HCl}, \geq 37 \%$; ethyl acetate (AcOEt), $\mathrm{H}_{2} \mathrm{SO}_{4}, 95-97 \%$; $p$-toluene sulfonic acid monohydrate ( $p$-TSA), $\geq$ 98.5\%; phenol, $\geq 99.5 \%$; methanol $(\mathrm{MeOH})$; 2,5-dihydroxybenzoic acid (DHB), $\geq 99.5 \%$; potassium trifluoroacetate, $98 \%$; dimethyl sulfoxide- $\mathrm{d}_{6}\left(\mathrm{DMSO}-\mathrm{d}_{6}\right)$ minimum deuteration degree 99.8\%; chloroform-d $\left(\mathrm{CDCl}_{3}\right)$, minimum deuteration degree $99.8 \%$.

Synthesis of 3-Chloro-2-hydroxypropanoic Acid (1). Compound (1) was synthesized according to literature procedure. ${ }^{29}$

Synthesis of 3-(4-Allyl-2-methoxyphenoxy)-2-hydroxypropanoic Acid (2). Eugenol $(4.75 \mathrm{~g}, 28.98 \mathrm{mmol})$ and sodium hydroxide (2.64 $\mathrm{g}, 66 \mathrm{mmol})$ were added to a dispersion of $1(2 \mathrm{~g}, 16.1 \mathrm{mmol})$ in 20 $\mathrm{mL}$ of water. The reaction mixture was heated to reflux and left under stirring for $2 \mathrm{~h}$. The solution was then acidified to $\mathrm{pH} 1$ with concentrated $\mathrm{HCl}$ and extracted with AcOEt $(4 \times 10 \mathrm{~mL})$, to obtain a mixture of product 2 and unreacted eugenol. The organic phases were collected and extracted with saturated aqueous $\mathrm{NaHCO}_{3}$ solution (4 $\times 10 \mathrm{~mL})$ in order to isolate the pure product. The aqueous phases were also collected, acidified with concentrated $\mathrm{H}_{2} \mathrm{SO}_{4}$ to reach $\mathrm{pH} 1$ and finally extracted with AcOEt $(4 \times 10 \mathrm{~mL})$. The organic phases were collected and dried over $\mathrm{Na}_{2} \mathrm{SO}_{4}$, and the solvent was evaporated under reduced pressure to obtain 2 as a dark orange viscous oil (3.00 g, 74\% yield). ${ }^{1} \mathrm{H}\left(\mathrm{NMR} 400 \mathrm{MHz}, \mathrm{DMSO}-\mathrm{d}^{6}\right) \delta: 6.90(\mathrm{~d}, J=8.1 \mathrm{~Hz}$, $1 \mathrm{H}), 6.79(\mathrm{~d}, J=2.0 \mathrm{~Hz}, 1 \mathrm{H}), 6.68(\mathrm{dd}, J=8.1,2.0 \mathrm{~Hz}, 1 \mathrm{H}), 5.95$ $(\mathrm{ddt}, J=16.8,10.0,6.7 \mathrm{~Hz}, 1 \mathrm{H}), 5.12-4.98(\mathrm{~m}, 2 \mathrm{H}), 4.31(\mathrm{dd}, J=$ $5.7,3.5 \mathrm{~Hz}, 1 \mathrm{H}), 4.08(\mathrm{~m}, 2 \mathrm{H}), 3.73(\mathrm{~s}, 3 \mathrm{H}), 3.30(\mathrm{~d}, J=6.7 \mathrm{~Hz}, 2 \mathrm{H})$. ${ }^{13} \mathrm{C}$ NMR (101 MHz, DMSO- $\left.d_{6}\right) \delta: 173.76,149.56,146.79,138.37$, $133.40,120.80,115.99,114.66,113.42,71.65,69.91,56.06,56.02 .{ }^{1} \mathrm{H}$ and ${ }^{13} \mathrm{C}$ NMR spectra of 2 are reported in Figures S1 and S2 in the Supporting Information.

Synthesis of 5-((4-Allyl-2-methoxyphenoxy)methyl)-2,2-dimethyl-1,3-dioxolan-4-one (EuDOX, 3). Compound $2(1.50 \mathrm{~g}, 5.96 \mathrm{mmol})$ was dissolved in acetone $(50 \mathrm{~mL})$. The solution was cooled to -10 ${ }^{\circ} \mathrm{C}$, and then concentrated sulfuric acid was added dropwise $(2.5 \mathrm{~mL})$.
Reaction was left under stirring for $4 \mathrm{~h} . \mathrm{NaHCO}_{3}$ was then added until $\mathrm{pH} 8$ was reached. Solid was filtered off and solvent removed under reduced pressure to obtain 3 as an orange solid (1.33 g, 76\% yield). ${ }^{1} \mathrm{H} \mathrm{NMR}\left(400 \mathrm{MHz}, \mathrm{CDCl}_{3}\right): 6.87(\mathrm{~d}, J=7.8 \mathrm{~Hz}, 1 \mathrm{H}), 6.72$ $(\mathrm{d}, J=7.9 \mathrm{~Hz}, 2 \mathrm{H}), 5.97(\mathrm{ddt}, J=16.9,10.2,6.7 \mathrm{~Hz}, 1 \mathrm{H}), 5.13-5.05$ $(\mathrm{m}, 2 \mathrm{H}), 4.79(\mathrm{dd}, J=4.5,2.5 \mathrm{~Hz}, 1 \mathrm{H}), 4.32(\mathrm{qd}, J=10.9,3.6 \mathrm{~Hz}$, 2H), $3.84(\mathrm{~s}, 3 \mathrm{H}), 3.35(\mathrm{~d}, J=6.7 \mathrm{~Hz}, 2 \mathrm{H}), 1.75(\mathrm{~s}, 3 \mathrm{H}), 1.63$ (s, $3 \mathrm{H}) .{ }^{13} \mathrm{C} \mathrm{NMR}\left(101 \mathrm{MHz}, \mathrm{CDCl}_{3}\right) \delta: 170.63,149.97,146.18,137.51$, $134.45,120.57,115.72$, 115.16, 112.98, 111.89, 74.41, 68.82, 55.94, 39.82, 26.88, 26.71. ${ }^{1} \mathrm{H}$ and ${ }^{13} \mathrm{C}$ NMR spectra of 3 are reported in Figures S3 and S4 in the Supporting Information.

Synthesis of 2-Hydroxy-3-phenoxypropanoic Acid (4). Phenol $(2.73 \mathrm{~g}, 28.98 \mathrm{mmol})$ and sodium hydroxide $(2.64 \mathrm{~g}, 66 \mathrm{mmol})$ were added to a dispersion of $1(2 \mathrm{~g}, 16.1 \mathrm{mmol})$ in $20 \mathrm{~mL}$ of water. The reaction mixture was heated to reflux and left under stirring for $2 \mathrm{~h}$.

The solution was then acidified to reach $\mathrm{pH} 1$ with concentrated $\mathrm{HCl}$ and extracted with AcOEt $(4 \times 10 \mathrm{~mL})$. The organic phases were collected and extracted with a saturated $\mathrm{NaHCO}_{3}$ solution $(4 \times 10$ $\mathrm{mL}$ ). The aqueous phases were then collected, acidified with $\mathrm{H}_{2} \mathrm{SO}_{4}$ to reach $\mathrm{pH} 1$ and finally extracted with AcOEt $(4 \times 10 \mathrm{~mL})$. The organic phases were collected and dried over $\mathrm{Na}_{2} \mathrm{SO}_{4}$, and the solvent was evaporated under reduced pressure to obtain 4 as a pale brown solid (2.32 g, 79\% yield). ${ }^{1} \mathrm{H}$ and ${ }^{13} \mathrm{C}$ NMR data were in agreement with the literature. ${ }^{30}$

Synthesis of 2,2-Dimethyl-5-(phenoxymethyl)-1,3-dioxolan-4one (PhDOX, 5). Compound $4(1.50 \mathrm{~g}, 5.96 \mathrm{mmol})$ was dissolved in acetone $(50 \mathrm{~mL})$. The solution was cooled to $-10{ }^{\circ} \mathrm{C}$, and then concentrated sulfuric acid was added dropwise $(2.5 \mathrm{~mL})$. The reaction was left under stirring for $4 \mathrm{~h} . \mathrm{NaHCO}_{3}$ was then added until $\mathrm{pH} 8$ was reached. The solid was filtered off, and the solvent was removed under reduced pressure to obtain 5 as a pale brown solid (1.43 g, 51\% yield). ${ }^{1} \mathrm{H} \mathrm{NMR}\left(400 \mathrm{MHz}, \mathrm{CDCl}_{3}\right) \delta: 7.31(\mathrm{dd}, J=8.8,7.4 \mathrm{~Hz}, 2 \mathrm{H})$, $7.01(\mathrm{tt}, J=7.3,1.1 \mathrm{~Hz}, 1 \mathrm{H}), 6.95(\mathrm{dd}, J=8.8,1.1 \mathrm{~Hz}, 2 \mathrm{H}), 4.78(\mathrm{dd}$, $J=4.2,2.4 \mathrm{~Hz}, 1 \mathrm{H}), 4.39-4.24(\mathrm{~m}, 2 \mathrm{H}), 1.72(\mathrm{~s}, 3 \mathrm{H}), 1.64(\mathrm{~s}, 3 \mathrm{H})$. ${ }^{13} \mathrm{C}$ NMR $\left(101 \mathrm{MHz}, \mathrm{CDCl}_{3}\right) \delta: 170.41,158.17,129.52,121.61$, $114.79,111.78,74.25,66.96,27.06,26.68 .{ }^{1} \mathrm{H}$ and ${ }^{13} \mathrm{C}$ NMR spectra of 5 are reported in Figures S5 and S6 in Supporting Information.

2,2-Dimethyl-5-(phenoxymethyl)-1,3-dioxolan-4-one (5) Polymerization Procedure. Compound $5(700 \mathrm{mg}, 3.14 \mathrm{mmol})$ was introduced in a round bottomed flask. $p$-TSA $(30 \mathrm{mg}, 0.157 \mathrm{mmol})$ was added thereafter. The mixture was heated to $150{ }^{\circ} \mathrm{C}$ under nitrogen atmosphere for $3 \mathrm{~h}$ to obtain a brown solid product.

EuDOX (3) Polymerization. Compound $3(750 \mathrm{mg}, 2.56 \mathrm{mmol})$ and $p$-TSA $(24.4 \mathrm{mg}, 0.128 \mathrm{mmol})$ were dissolved in $3 \mathrm{~mL}$ of AcOEt. As soon as both the monomer and the catalyst were completely dissolved, they were poured in an aluminum mold and the solvent was left to evaporate overnight. The curing process was then performed, by heating at $150{ }^{\circ} \mathrm{C}$ for $3 \mathrm{~h}$, to obtain a dark orange transparent film.

Microwave Degradation. Thermoset degradation was conducted in a microwave oven named flexiWAVE from Milestone, Inc. Two solvents were tested as degradation medium: water and methanol. In addition to degradation in pure solvents, the effect of $\mathrm{NaOH}$ addition was evaluated $(0.5 \% \mathrm{w} / \mathrm{w})$. On the basis of optimization of the general degradation conditions in an earlier work with other aliphatic polyesters, ${ }^{31} 200 \mathrm{mg}$ of product was degraded by heating for $1 \mathrm{~h}$ either at $150{ }^{\circ} \mathrm{C}$ (water) or $110{ }^{\circ} \mathrm{C}$ (methanol). The degradation temperatures were reached after a ramp time of $3 \mathrm{~min}$ in both cases. Input irradiation power was varied automatically to reach and keep the specified temperatures.

Nuclear Magnetic Resonance (NMR). The $400 \mathrm{MHz}{ }^{1} \mathrm{H}$ NMR and $100 \mathrm{MHz}{ }^{13} \mathrm{C}$ NMR spectra were recorded on a Bruker Advance 400 spectrometer at $298 \mathrm{~K}$.

Matrix-Assisted Laser Desorption/Ionization-Mass Spectrometry (MALDI-MS). For the measurements, a Bruker UltraFlex time-of-flight (TOF) mass spectrometer with a SCOUT-MTP ion source and equipped with a $337 \mathrm{~nm}$ nitrogen laser was used in reflector mode. Before analysis, the samples $(1 \mathrm{mg} / \mathrm{mL})$, the matrix, DHB $(10 \mathrm{mg} / \mathrm{mL})$, and the salt potassium trifluoroacetate $(1 \mathrm{mg} /$ $\mathrm{mL}$ ) solutions in $\mathrm{MeOH}$ were mixed and drop casted on a stainless steel MALDI plate in a volume of $8 \mu \mathrm{L}$. 
Scheme 1. Synthesis of the Two DOX Monomers ${ }^{a}$

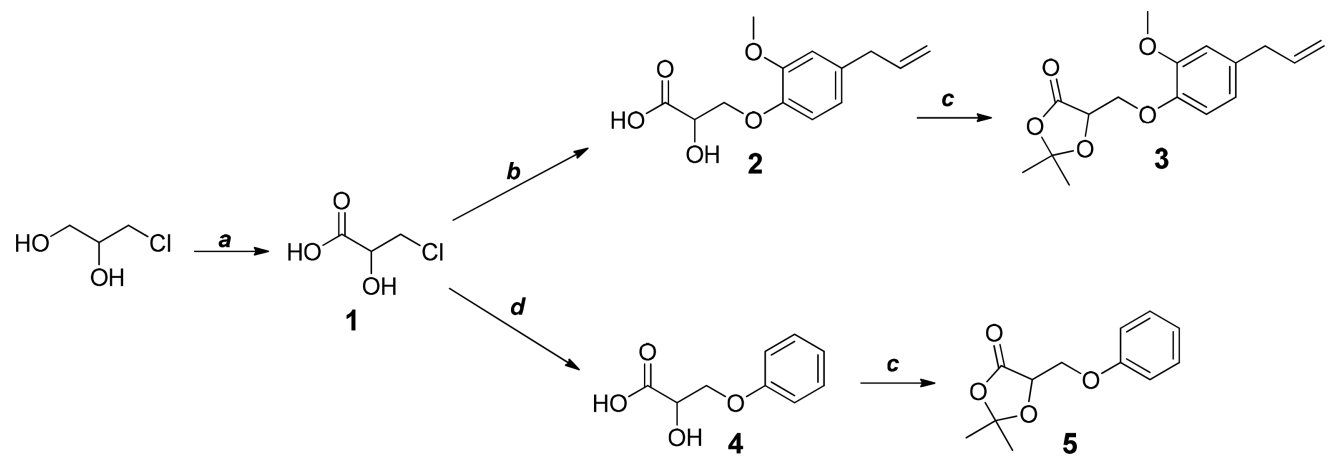

${ }^{a}$ Reagents and Conditions: (a) $\mathrm{HNO}_{3}$, heating; (b) eugenol, $\mathrm{NaOH}, \mathrm{H}_{2} \mathrm{O}$, reflux, $2 \mathrm{~h}$; (c) acetone, $\mathrm{H}_{2} \mathrm{SO}_{4}$, 4h; (d) phenol, $\mathrm{NaOH}, \mathrm{H}_{2} \mathrm{O}$, reflux, 2 h.

Fourier Transform Infrared Spectroscopy (FTIR). FTIR was done on a PerkinElmer Spectrum 100 with 16 scans from 4000 to 600 $\mathrm{cm}^{-1}$ through a resolution of $4 \mathrm{~cm}^{-1}$. The golden gate was from Graseby Specac (Kent, UK), and the software PerkinElmer Spectrum was used to process the data.

Differential Scanning Calorimetry (DSC). Mettler-Toledo 820 was utilized to conduct the measurements. Five mg of each sample was placed in a $100 \mu \mathrm{L}$ aluminum cup with a pinhole on the lid. The applied heating rate was $10^{\circ} \mathrm{C} \mathrm{min}-1$ in a nitrogen atmosphere (rate $50 \mathrm{~mL} \mathrm{~min}{ }^{-1}$ ). Thermal behavior was investigated using the following temperature cycles: (1) heating from 25 to $200{ }^{\circ} \mathrm{C}$; (2) $5 \mathrm{~min}$ isotherm at $200{ }^{\circ} \mathrm{C}$; (3) cooling from 200 to $25{ }^{\circ} \mathrm{C}$; (4) $2 \mathrm{~min}$ isotherm at $25{ }^{\circ} \mathrm{C}$; (5) heating from 25 to $200{ }^{\circ} \mathrm{C}$.

The first heating and cooling cycle was run to eliminate residual internal stresses deriving from the thermoset preparation.

Thermogravimetric Analysis (TGA). Mettler-Toledo TGA/ SDTA 851e was utilized for thermal analysis. Five mg of each sample was placed into a $70 \mu \mathrm{L}$ alumina cup and heated at a rate of $10{ }^{\circ} \mathrm{C}$ $\mathrm{min}^{-1}$. The measurements were performed under $80 \mathrm{~mL} \mathrm{~min}{ }^{-1}$ nitrogen flow.

Size Exclusion Chromatography (SEC). Verotech PL-GPC 50 Plus system equipped with a PL-RI Detector and two PLgel $5 \mu \mathrm{m}$ MIXED-D $(300 \times 7.5 \mathrm{~mm})$ columns from Varian were employed for the measurements. Chloroform was used as the mobile phase $(1 \mathrm{~mL}$ $\min ^{-1}, 30^{\circ} \mathrm{C}$ ) and toluene as an internal standard to correct for flow rate fluctuations. The calibration was based on polystyrene standards with a narrow molecular weight ranging from 160 to $371000 \mathrm{~g} / \mathrm{mol}$.

Gel Content Test. To determine the gel content $\approx 500 \mathrm{mg}$ of the product was extracted with $\mathrm{CHCl}_{3}(\approx 5 \mathrm{~mL})$ for $24 \mathrm{~h}$. The insoluble fraction was dried at $30{ }^{\circ} \mathrm{C}$ until constant weight was reached. Gel content was then calculated, following eq 1.

$$
\text { gel content } \%=\frac{m_{\mathrm{ae}}}{m_{\mathrm{be}}} 100
$$

where $m_{\mathrm{ae}}$ indicates the sample weight after extraction and $m_{\mathrm{be}}$ is the sample weight before extraction.

Tensile Testing. The testing was conducted on an INSTRON 5944 module equipped with pneumatic grips. A $500 \mathrm{~N}$ load cell was used for the measurements with a gauge length of $10 \mathrm{~mm}$, and a crosshead speed of $5 \mathrm{~mm} / \mathrm{min}$ was applied. The samples were cut into strips of width $0.5 \mathrm{~cm}$ with a thickness of an average of $0.1 \mathrm{~mm}$. Before analysis, the test strips were preconditioned according to ASTM D618-96 (40 h at 50\% $\pm 5 \%$ relative humidity and $23{ }^{\circ} \mathrm{C} \pm 1$ ${ }^{\circ} \mathrm{C}$ ).

Antimicrobial Testing. The thermoset was crushed into pieces with mortar. Three different concentrations were tested: $1000 \mu \mathrm{g}$ $\mathrm{mL}^{-1}$ and 2 dilution series: 500 and $250 \mu \mathrm{g} \mathrm{mL}^{-1}$. The thermoset at the highest concentration was compared with washed pieces of thermoset at the same concentration. The washing was performed in ethanol $70 \%$ for $30 \mathrm{~min}$. Thereafter, the ethanol was decanted off and the pieces were left to dry before testing was performed. The bacteria
E. coli were harvested in midexponential phase and the tests were performed according to macrodilution in a bacteria concentration of $10^{7} \mathrm{CFU} \mathrm{mL} \mathrm{m}^{-1}$. A $100 \mu \mathrm{L}$ sample of the bacteria suspension (107 $\mathrm{CFU} \mathrm{mL} \mathrm{m}^{-1}$ ) was transferred to $10 \mathrm{~mL}$ of LB broth. Two milliliters of this suspension was then added into glass vials of three replicates. Bacteria suspensions were used as negative control, and two types of antibiotics in tablet form with a loading of $10 \mu \mathrm{g}$ were used as positive controls. The bacteria suspensions with and without material were placed in an incubator at $70 \mathrm{rpms}$ for $24 \mathrm{~h}$. At time 0 , the suspensions were transparent and gave an OD value of 0.0467 . Then the OD was measured again after 12,19 , and $24 \mathrm{~h}$.

\section{RESULTS AND DISCUSSION}

The efficacy of 1,3-dioxolan-4-one monomers (DOX) for the preparation of PLA materials was previously highlighted. ${ }^{22}$ Here the scope of DOX monomers was broadened to the synthesis of high-performance polyester thermosets through functionalization by eugenol. Microwave-assisted hydrothermal degradation of the thermoset was also performed to obtain proof concerning the chemical structure and recyclability.

Synthesis of Monomers. The two DOX monomers, EuDOX 3 and PhDOX 5, were synthesized starting from 3chloro-1,2-dihydroxypropanediol, through the common intermediate 3-chloro-2-hydroxypropanoic acid $\mathbf{1}$ (Scheme 1). Compound 1 was then reacted with eugenol or phenol to obtain respectively the phenolic ethers $\mathbf{2}$ and $\mathbf{4}$, achieved in high purity and in good yield. Subsequent $\alpha$-hydroxy acid protection with acetone allowed acquisition of the DOX monomers 3 and $\mathbf{5}$.

Proof of Concept for Polymerization of DOX with bulky side group: PhDOX polymerization. First polymerization of $\mathrm{PhDOX}$ was attempted, to prove the feasibility of the polyester formation from DOX monomers bearing a bulky side group. Since a rising difficulty has been reported in aluminum salen-catalyzed polymerization of 1,3-dioxolan-4-ones as the bulkiness of the side group increases, ${ }^{22}$ we looked at a less cumbersome catalyst, namely Brønsted $p$-toluene sulfonic acid ( $p$-TSA).

The polymerization reaction was first tested on PhDOX, utilized as a model monomer lacking additional reactive groups. Reaction was conducted in bulk, using p-TSA as catalyst with a $20: 1$ monomer-to-catalyst molar ratio $(5 \% \mathrm{~m} /$ $\mathrm{m})$ at $150{ }^{\circ} \mathrm{C}$ for $3 \mathrm{~h}$ under nitrogen atmosphere (Scheme 2 ). The reaction successfully yielded an oligomeric product (2000 $\mathrm{g} / \mathrm{mol}$ according to SEC analysis). The ${ }^{1} \mathrm{H}$ NMR spectrum with peak assignments is shown in Figure 1. 
Scheme 2. Polymerization of Monomer PhDOX

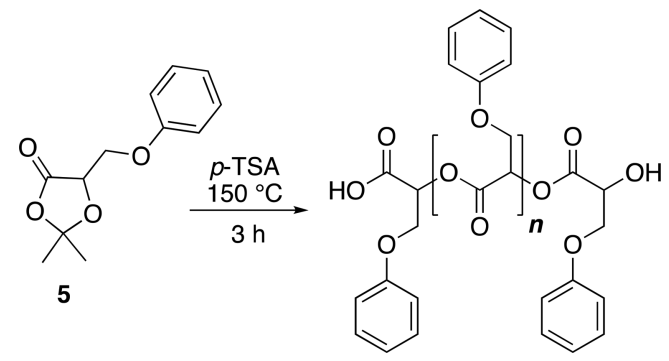

EuDOX Polymerization. Catalyst-to-Monomer Ratio Screening. The same reaction protocol was then applied to EuDOX. This yielded an insoluble product, indicating that a cross-linking reaction likely occurred, resulting in a thermoset material. Encouraged by this outcome, the efforts were concentrated on screening the best reaction conditions and then evaluating the properties of the obtained eugenol-derived material.

First, a small survey on the optimal monomer to catalyst ratio was performed. Reactions were carried out varying the catalyst to monomer ratio, followed by determination of the gel content according to the procedure reported in the Experimental Section. The gel content of a thermoset is an important parameter that indicates the amount of cross-linked material in the product, and therefore it can indicate the efficiency of the curing reaction. Four different catalyst concentrations were tested, and the respective gel content of the product was determined and reported in Table 1.

Table 1. Optimization of Catalyst to Monomer Ratio and the Resulting Gel Content

\begin{tabular}{ccc} 
sample & catalyst concentration $(\mathrm{mol} \%)$ & gel content $(\%)$ \\
TS0 & 0 & 0 \\
TS1 & 1 & 31 \\
TS5 & 5 & 89 \\
TS10 & 10 & 90 \\
\hline
\end{tabular}

As shown by the data in Table 1, there was a relationship between the catalyst concentration and the gel content. Starting from the TS0 sample, with $0 \mathrm{~mol} \%$ catalyst concentration, no cross-linking reaction took place. By increasing the catalyst concentration to $1 \mathrm{~mol} \%$, some crosslinking took place, but the extent was low resulting in only $31 \%$ gel content. Regarding the TS5 and TS10 samples with 5 or 10 mol \% catalyst they both exhibited high and comparable gel content of around $90 \%$. Considering that no significant differences were registered between TS5 and TS10 samples, the lower catalyst concentration, that is, $5 \mathrm{~mol} \%$ was selected as the catalyst concentration for further studies and material production.

Film Preparation. To obtain a film for evaluation of mechanical properties, an ethyl acetate solution of monomer and catalyst $(5 \% \mathrm{~m} / \mathrm{m}$ loading) was prepared and poured into

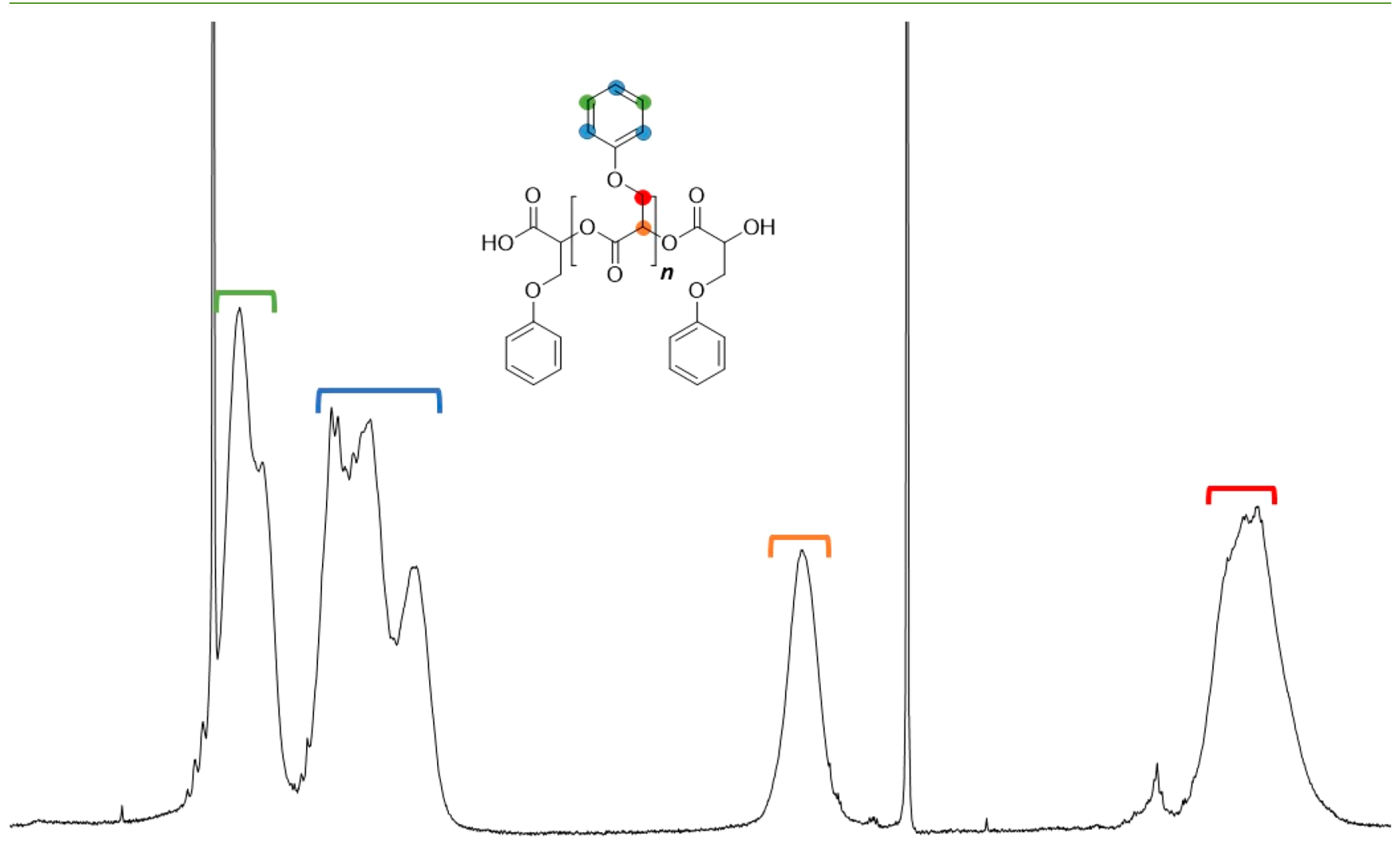

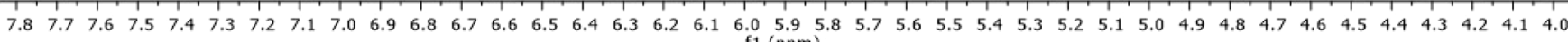
f1 ( $\mathrm{ppm})$

Figure 1. ${ }^{1} \mathrm{H}$ NMR spectrum of the polymerization product of monomer $\mathbf{5}$. 
an aluminum mold, as shown in Figure 2. The solution was originally transparent (Figure $2 \mathrm{a}$ ). The solvent was evaporated
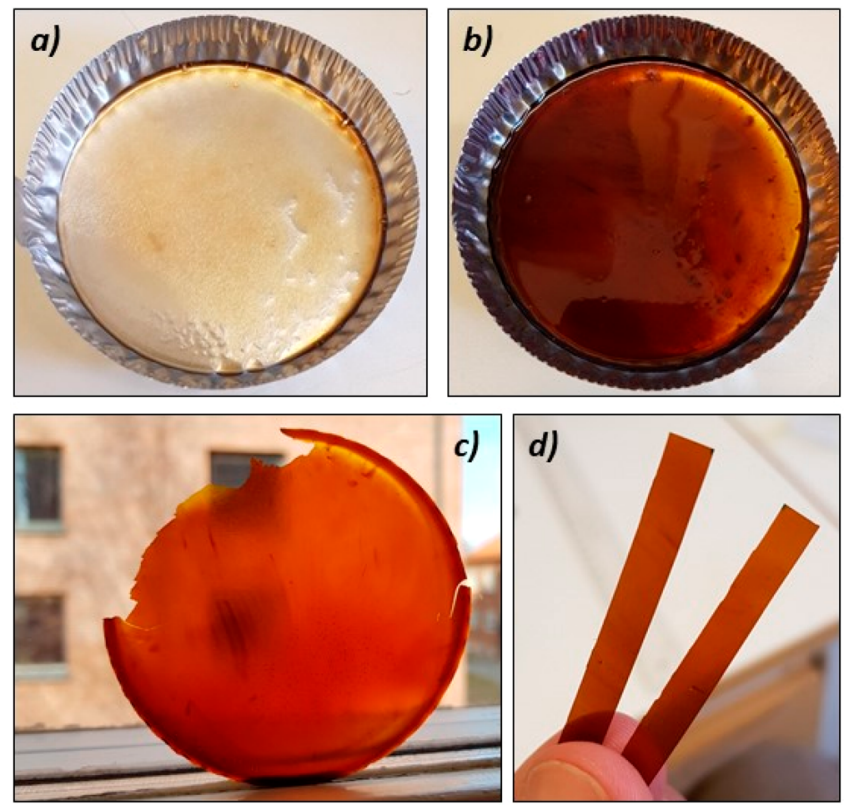

Figure 2. (a) Monomer/catalyst mixture after AcOEt overnight evaporation; (b) cured product; (c) cured film out of the mold; (d) strips cut out of the cured film.

overnight at $30{ }^{\circ} \mathrm{C}$ in vacuum and the curing was then performed in an oven at $150{ }^{\circ} \mathrm{C}$ for $3 \mathrm{~h}$ (Figure $2 \mathrm{~b}$ ). After curing the film was dark brown or orange due to the exposure to air at elevated temperature. The transparent and homogeneous film could then be removed from the mold (Figure 2c) and thin stripes were cut from the film, suited for tensile testing (Figure 2d).

Tensile Testing. The mechanical properties of the cured thermoset were evaluated by tensile testing. The thermoset showed a tensile strength at break of $70.8 \pm 0.7 \mathrm{MPa}$. This is a top end value among commercial polyester-based thermosets and previously described biobased thermosets. The material proved to be extremely stiff, with a very low tensile strain (1.4 $\pm 0.2 \%)$ and an extremely high Young's modulus $(8.8 \pm 0.2$ $\mathrm{GPa}$ ) probably due to the high aromatic content resulting from eugenol functionalization. Table 2 reports these values (a) in comparison with those described for typical biobased thermosets. $6,17,32-34$

Table 2. Comparison of the Mechanical Properties of the Cured Thermoset (a) with Previously Reported Biobased Thermosets

\begin{tabular}{|c|c|c|c|}
\hline thermoset & $\begin{array}{c}\text { Young's } \\
\text { modulus (MPa) }\end{array}$ & $\begin{array}{c}\text { tensile strength at } \\
\text { break }(\mathrm{MPa})\end{array}$ & $\begin{array}{c}\text { tensile strain } \\
(\%)\end{array}$ \\
\hline $\mathrm{a}$ & $8765 \pm 19$ & $70.8 \pm 0.7$ & $1.4 \pm 0.2$ \\
\hline $\begin{array}{l}\text { itaconic acid- } \\
\text { based }^{6}\end{array}$ & $398 \pm 6.6$ & $15.0 \pm 3.0$ & $6 \pm 1$ \\
\hline PLA-based ${ }^{17}$ & & $57.3 \pm 2.6$ & $4.03 \pm 0.19$ \\
\hline $\begin{array}{l}\text { natural triphenol- } \\
\text { based }^{32}\end{array}$ & & 80.0 & 2.68 \\
\hline $\begin{array}{l}\text { diphenolate ester- } \\
\text { based }^{33}\end{array}$ & $1306 \pm 69$ & $68.7 \pm 6.3$ & $9.3 \pm 1.4$ \\
\hline cardanol-based $^{34}$ & & $73.2 \pm 1.4$ & $10.7 \pm 0.3$ \\
\hline
\end{tabular}

Microwave-Assisted Degradation of the Thermoset. Due to the nonsolubility of the thermoset materials it is generally difficult to prove their exact chemical structure.

In earlier work it was demonstrated that ester bonds in poly(3-hydroxybutyrate) can be effectively hydrolyzed by the microwave-assisted process. ${ }^{31}$ The thermoset synthesized here was subjected to similar microwave-assisted process aiming to elucidate and shed light on its chemical structure. In addition, the degradability and potential recyclability of the thermosets to functional chemicals or intermediates for new material production is of high interest to move forward toward circular society and circular materials. Four different degradation tests were performed, respectively, in water, methanol, alkaline water, and alkaline methanol.

The microwave process in alkaline water and alkaline methanol resulted in complete degradation of the thermoset to water or methanol soluble products with no remaining solid residue. The thermoset degraded partially during the microwave-process in pure water or methanol, but some nondegraded solid product remained. The alkaline solutions were acidified to $\mathrm{pH} 1$ with sulfuric acid and extracted with AcOEt. After solvent evaporation the residues were characterized through ${ }^{1} \mathrm{H}$ NMR, MALDI-TOF, and FT-IR.

${ }^{1} \mathrm{H}$ NMR Analysis of the Degradation Products from the Microwave Process. The ${ }^{1} \mathrm{H}$ NMR spectrum for the degradation products after microwave processing in alkaline methanol was recorded (Figure 3). Even if an exhaustive interpretation of the spectrum was not possible given the complexity of the degradation mixture and hence of the signal patterns, the spectrum gives good indication of the occurred cross-linking and provides insights into the chemical structure of the thermoset.

First of all, both carboxylic $-\mathrm{OH}$ as well as alcoholic $-\mathrm{OH}$ signals can be detected at 12.5 and 5.5 ppm, respectively. Free $\alpha$-hydroxyl acid groups are therefore likely to be present after degradation. No signals for allyl groups are detectable, while signals are present in the high field aliphatic region (see expansions in Figure 3). The presence of olefinic proton singlets around the $6.2 \mathrm{ppm}$ area gives evidence for the actual occurrence of a reaction at the eugenol double bonds. In particular, a cationic polymerization mechanism can be hypothesized, starting from the protonation of the allylic double bond, to give the expected secondary carbocation, but also the rearranged benzylic one. Indeed, hydride shift is likely to take place in the reaction conditions, resulting in head-to-tail reaction, as the structure depicted in Figure 3 illustrates. Termination through proton transfer then generates the terminal double bond. The ${ }^{1} \mathrm{H}$ NMR spectrum of the degradation products after microwave-assisted degradation in alkaline water does not show any significant differences with respect to the reported one. It is, however, reasonable to expect some methanolysis products after degradation in methanol. Signals relative to methyl esters or ethers would fall in the 3.5$4.5 \mathrm{ppm}$ region, but the possible presence of these species cannot be safely disclosed.

MALDI-TOF Analysis of the Degradation Products from the Microwave Process. MALDI-TOF analysis confirmed extensive degradation by the exclusive appearance of compounds with very low overall molecular weights. The $\mathrm{m} /$ $z$ value of the peaks with the highest intensity can be ascribed to dimer structures as those reported in Figure 4, confirming what was already hypothesized by NMR. Alongside this main series, the corresponding trimers could be detected with $\mathrm{m} / z=$ 


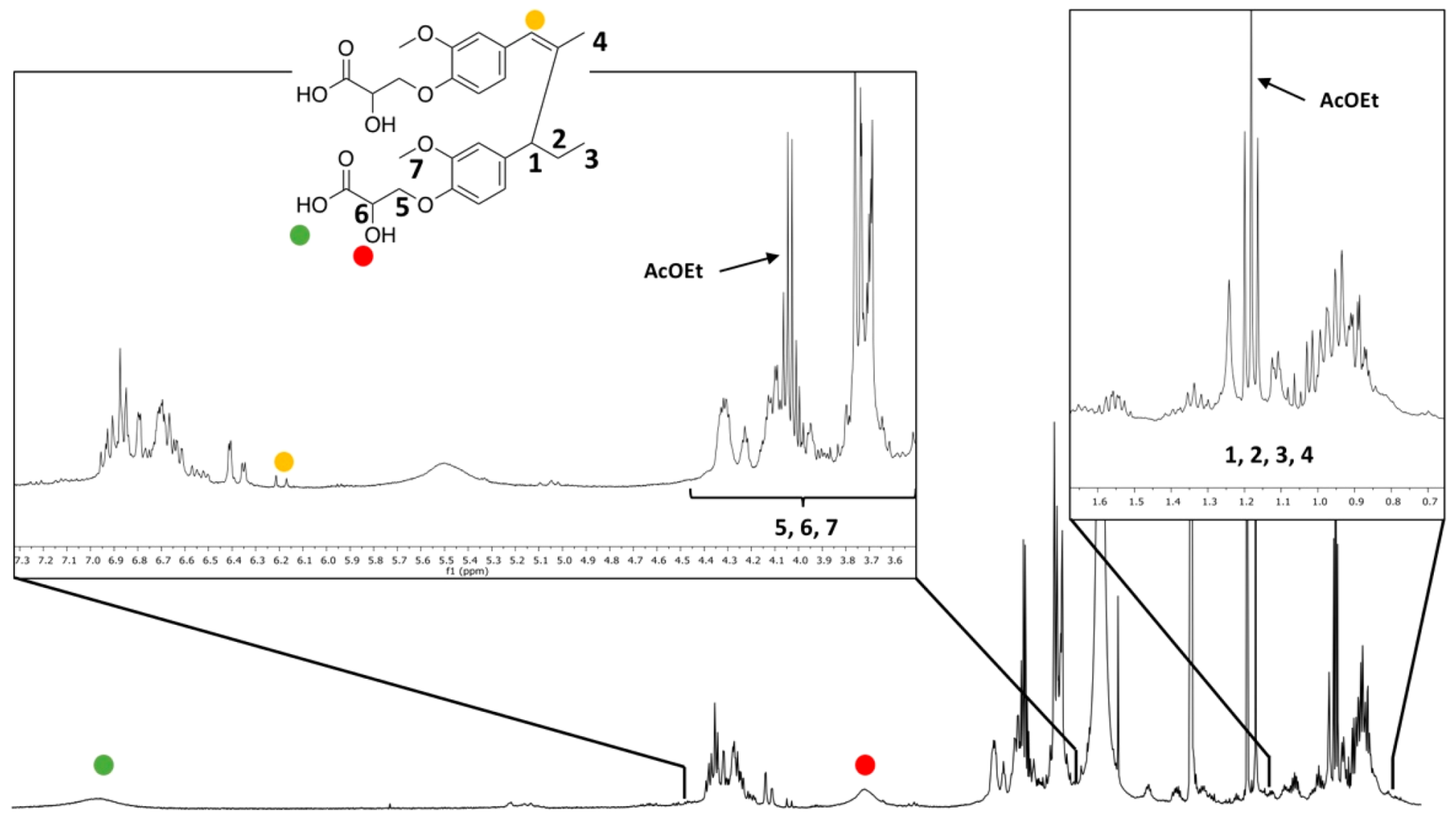

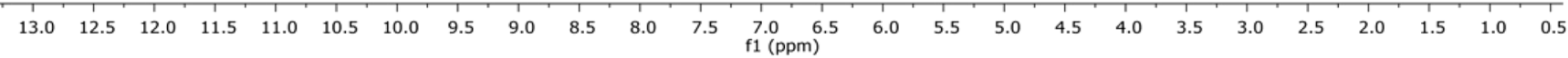

Figure 3. ${ }^{1} \mathrm{H}$ NMR spectrum of the degradation products after microwave processing in alkaline methanol with $0.5 \% \mathrm{w} / \mathrm{w} \mathrm{NaOH} / \mathrm{methanol}$.

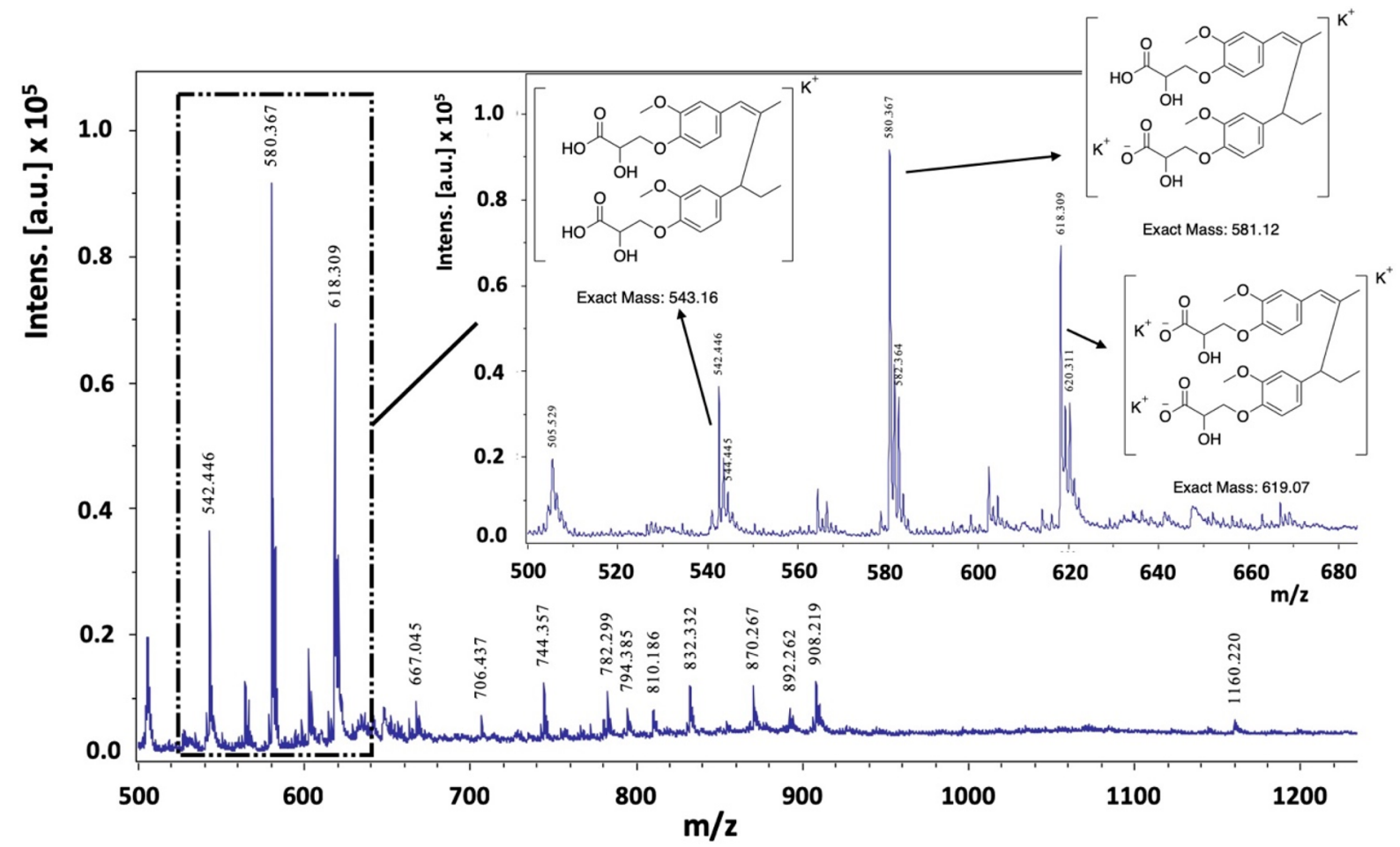

Figure 4. MALDI-TOF spectrum of degradation products after the microwave-assisted degradation in alkaline methanol.

794, 832, 870, and 908, respectively. The formation of degradation products bearing free $\alpha$-hydroxy acid groups supports the expected formation of polyester during the curing reaction, that is, a structure that can be hydrolyzed during the 


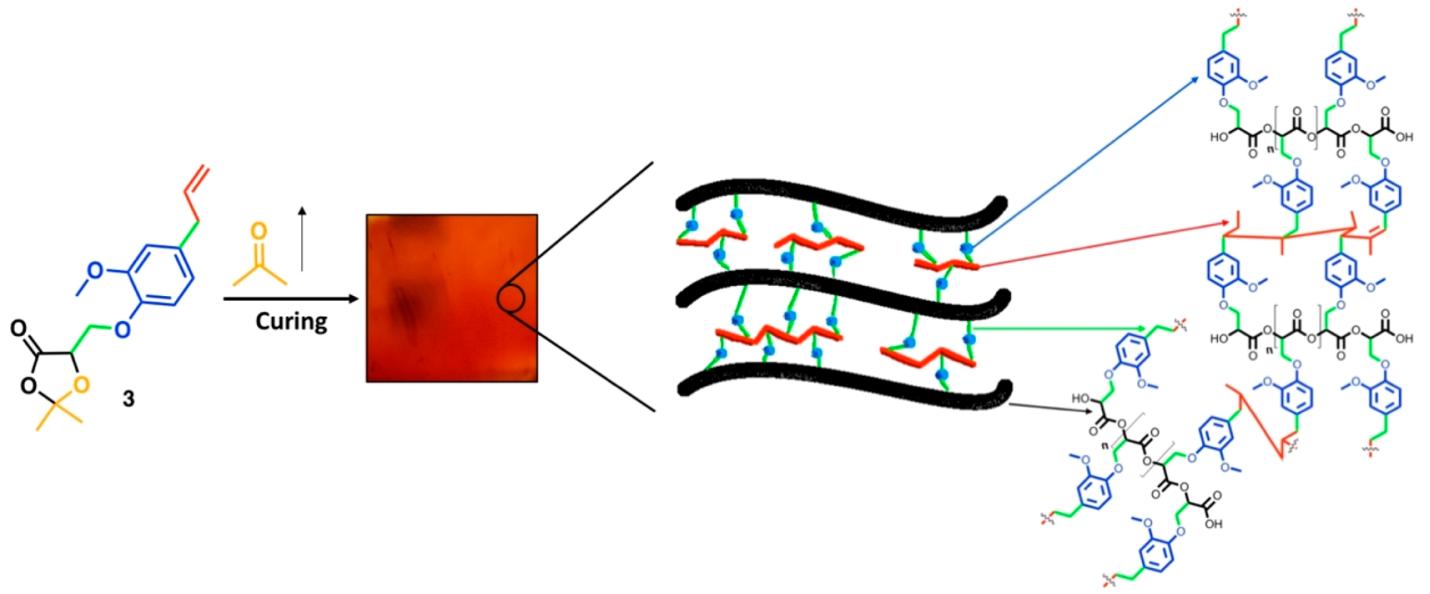

Figure 5. Proposed structure and schematic representation of the synthesized thermoset.

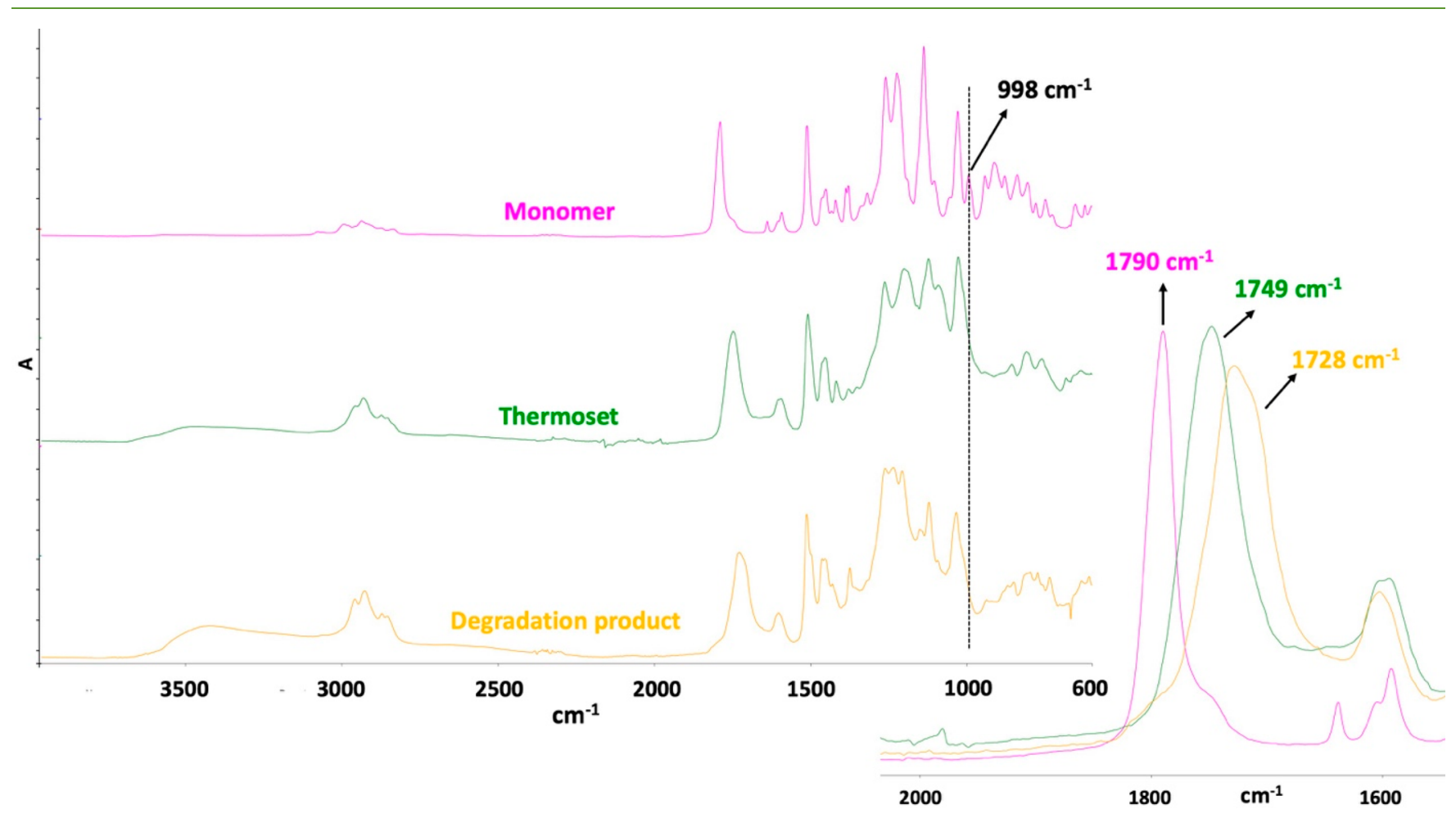

Figure 6. Comparison of the FTIR spectra of the monomer, thermoset, and degradation products.

MW-assisted degradation. The cross-linking, likely occurring by the double bond polymerization, could lead to different C$\mathrm{C}$ bonds, for instance through occurrence of allylic polymerization, affording degradation fragments that would fit with NMR and MALDI-TOF outputs. A possible structure for the thermoset is reported in Figure 5, taking into account all these reaction possibilities.

To fully demonstrate the reactivity of eugenol allyl moiety, a reaction of eugenol only in the same conditions was carried out. Also in this case the complete disappearance of double bonds is registered, with the formation of a great number of signals in the aliphatic region $\left({ }^{1} \mathrm{H}\right.$ NMR spectrum of the obtained product is reported in Figures S7 and S8 in the Supporting Information).

Analysis of the Degradation Products from the Microwave Process by FT-IR. Further proof regarding the chemical structure of the thermoset came from FT-IR analyses.
A comparison of the spectra for the monomer, the cured material, and the degradation product is reported in Figure 6.

Both the thermoset and the degradation products showed a broad $\mathrm{O}-\mathrm{H}$ stretching band, centered at $3440 \mathrm{~cm}^{-1}$. In the case of the thermoset, it can be attributed to the presence of surface free hydroxyl and carboxyl groups. In the degradation product spectrum the same band is present, but with significantly greater intensity, due to the massive formation of free $-\mathrm{OH}$ and $-\mathrm{COOH}$ groups. In the $2000-1600 \mathrm{~cm}^{-1}$ region the shift of the $\mathrm{C}=\mathrm{O}$ stretching peak gives confirmations about the reaction. While in the monomer it is sharp and centered at $1790 \mathrm{~cm}^{-1}$, it shifts to $1749 \mathrm{~cm}^{-1}$ for the thermoset, confirming the formation of the polyester. Finally, after the degradation, the carbonyl peak shifted further to 1728 $\mathrm{cm}^{-1}$, as a result of the presence of carboxylic acid functional groups. In addition, in the monomer spectrum it is possible to highlight the peak relative to the terminal $\mathrm{C}-\mathrm{H}$ bending for 


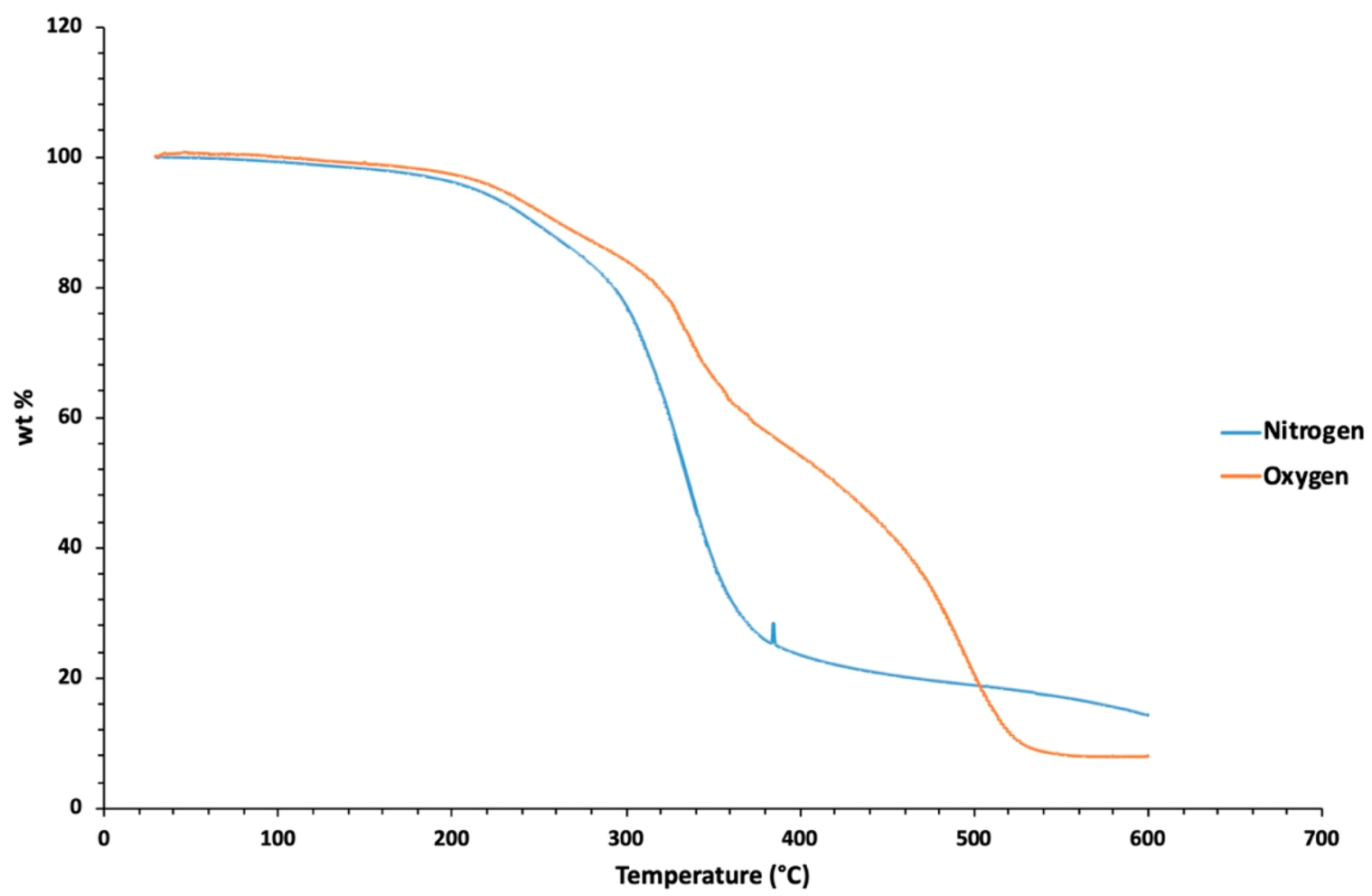

Figure 7. TGA curves showing the thermoset degradation in both nitrogen and oxygen atmosphere.

the allyl group at $1000 \mathrm{~cm}^{-1}$. In both thermoset and degradation product spectra this peak cannot be detected, confirming the reaction of the double bond during the curing process.

Thermal Analyses. DSC analysis was performed in order to determine both the curing kinetics and the thermal properties of the thermoset. The curing reaction proceeded for $75 \mathrm{~min}$ after the temperature of $150{ }^{\circ} \mathrm{C}$ was reached. After 75 min a plateau region was observed indicating that the curing reaction was completed. DSC analysis was also run on the product cured in a mold, in order to determine its thermal behavior. The related thermogram is reported in Supporting Information. The second heating scan shows a glass transition at $125{ }^{\circ} \mathrm{C}$. Glass transition could also be detected during the cooling step. As expected and typical for thermosets, the material seemed completely amorphous and no melting peak was detected at least during heating up to $200{ }^{\circ} \mathrm{C}$.

TGA curves relative to the degradations in both nitrogen and oxygen atmosphere are reported in Figure 7 . Temperatures relative to $5 \%$ weight loss $\left(T_{95 \%}\right)$ and $50 \%$ weight loss $\left(\mathrm{T}_{50 \%}\right)$, as well as the weight residue at $600{ }^{\circ} \mathrm{C}$ are reported in Table 3 for both experiments.

The two degradation curves have significantly different profiles. The TGA analysis run in nitrogen atmosphere shows a faster two-step weight loss at a relatively narrow temperature range, as well as a greater residue at the end of the analysis. In the TGA analysis run in oxygen three-step degradation can be

Table 3. Degradation Data from the Thermogravimetric Analysis in Nitrogen and Oxygen

\begin{tabular}{lccc}
\multicolumn{1}{c}{ gas } & $T_{95 \%}\left({ }^{\circ} \mathrm{C}\right)$ & $T_{50 \%}\left({ }^{\circ} \mathrm{C}\right)$ & wt $\%$ residue at $600{ }^{\circ} \mathrm{C}$ \\
nitrogen & 213.9 & 335.6 & 14.2 \\
oxygen & 227.3 & 420.6 & 8.0
\end{tabular}

observed. Considering the $5 \%$ weight loss as the beginning of the degradation, it can be argued that the thermoset showed higher thermal stability when the analysis was run in oxygen atmosphere. Furthermore, looking at $T_{50 \%}$, a significant difference is present, with the thermoset losing $50 \%$ of its mass at an 85 degrees higher temperature when the analysis was conducted in oxygen rather than in nitrogen atmosphere. The reason behind this behavior could be found in the possible occurrence of oxygen-promoted reactions at high temperature. For instance, the possible formation of a reactive species could lead to new cross-linking reactions, likely resulting in a higher thermal resistance. This hypothesis seems reasonable also when looking at the degradation profiles, where the two first degradation steps seem to partially coincide irrespective of whether the analysis was performed in nitrogen or oxygen atmosphere. In both atmospheres, these two steps occur at very similar temperatures, namely at around 240 and $330{ }^{\circ} \mathrm{C}$ respectively. However, in relation to the weight loss observed, the second-step is much smaller when the degradation is performed in oxygen atmosphere. At the same time the process expands to somewhat higher temperature, which could indicate formation of more stable species during the degradation process. These species are finally degraded during the third step, occurring at $500{ }^{\circ} \mathrm{C}$.

Shape Memory and Self-Healing Properties. Previous studies demonstrated that the presence of free surface carboxyl and hydroxyl functionalities can lead to shape memory and self-healing properties. ${ }^{35,36}$ Therefore, the shape memory and self-healing properties of the synthesized thermoset were also evaluated.

First the thermoset was subjected to thermal treatment at $150{ }^{\circ} \mathrm{C}$. Figure 8 shows how the planar and flexible thermoset film changed shape during the thermal treatment. The new shape was then retained when the material was cooled back to 


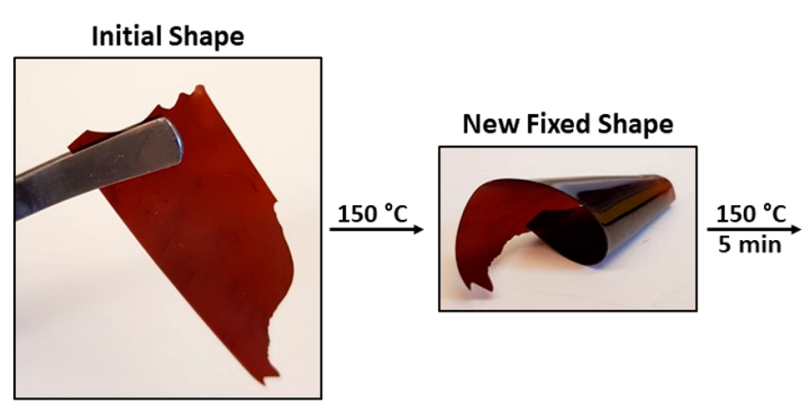

Back to Initial Shape

Figure 8. Shape memory behavior at high temperature.

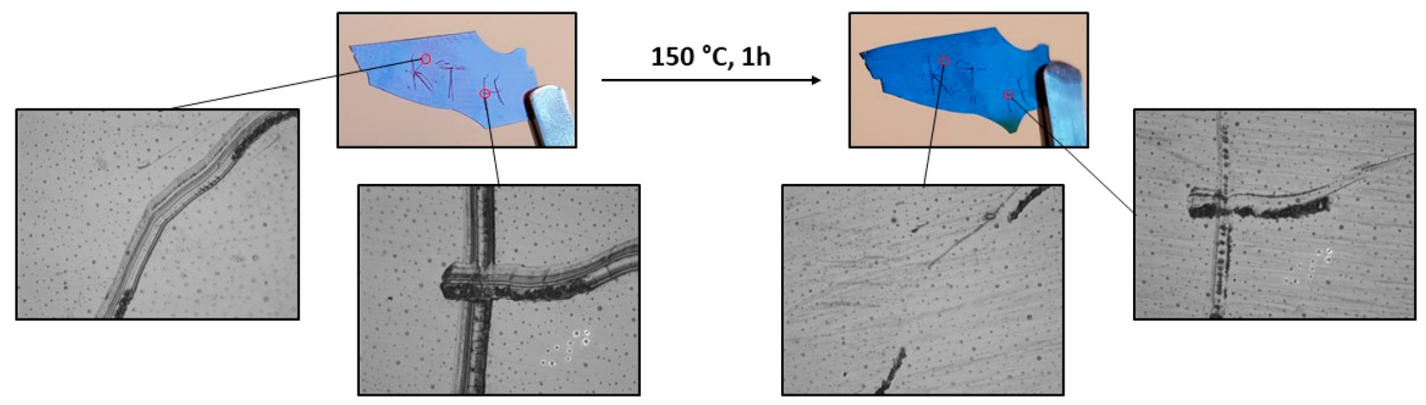

Figure 9. Self-healing properties tested by scratching the surface of the thermoset film followed by heating.

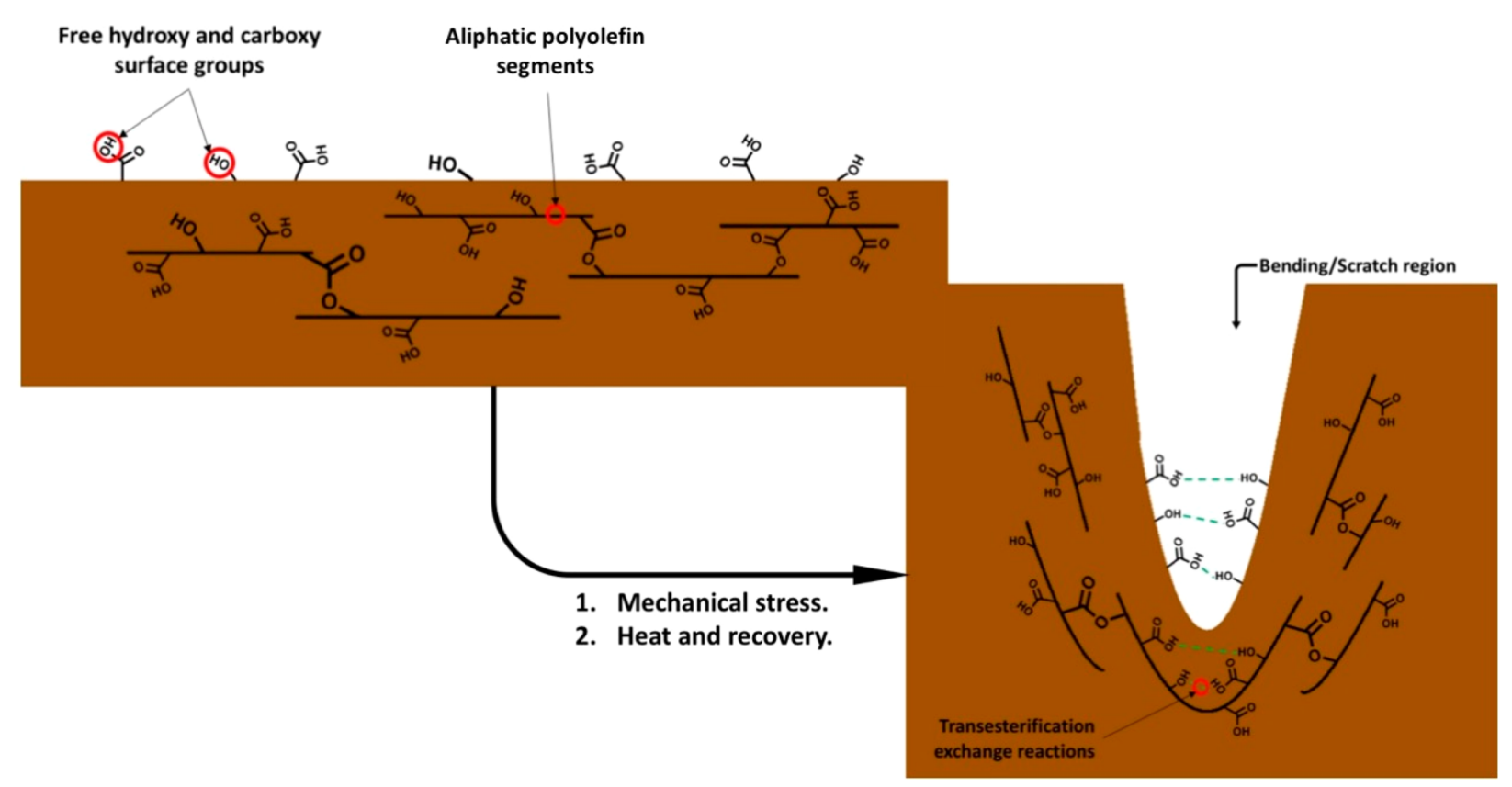

Figure 10. Schematic representation of possible mechanism behind the shape memory and self-healing capabilities.

room temperature. However, when heated again the thermoset returned back to the original shape of planar film.

Finally, the self-healing capability of the thermoset was evaluated by scratching the surface and then subjecting the material to elevated temperature at $150{ }^{\circ} \mathrm{C}$ to facilitate the chemical reactions leading to self-healing behavior. Figure 9 illustrates the scratched surface and the partially self-healed material after the thermal treatment. It can be observed that superficial scratches were repaired after $1 \mathrm{~h}$ heating at $150{ }^{\circ} \mathrm{C}$, while the deeper scratches partially remained.
Transesterification exchange reactions have been reported to bear the main responsibility for self-healing and shape memory properties of polyester-containing thermosets. ${ }^{36}$ Owing to the formation of potentially reversible links at high temperatures, the network structure can change while keeping the number of chemical bonds constant. Unlike many other polyester-based thermosets, the thermoset presented here can also benefit from the presence of short hydrocarbon segments or cross-links that are stable at temperatures around $150{ }^{\circ} \mathrm{C}$. These nonaffected bonds can give increased stability to the system and play a crucial role in the shape memory properties, helping the system 
to go back to the initial shape by acting as a stable frame. In addition, the greater flexibility of polyolefin structures with respect to the polyester backbone can allow easier structural rearrangement during the transesterification exchange reactions. On the other hand, the stability of these bonds and their inability to undergo transient reactions can restrict the selfhealing properties.

Figure 10 reports a schematic representation of the possible mechanism behind shape memory and self-healing properties of the prepared thermosets. Basically free hydroxy and carboxy surface groups can combine through transesterification exchange reactions at high temperatures, providing shape memory and self-healing capabilities. Aliphatic polyolefin segments can bend but not rearrange. This results in a tendency of the material to go back to the initial shape. At the same time it could hinder the recovery of deeper scratches, due to the reduced mobility given by both the aromatic rings and the shortness of these segments.

Antimicrobial Testing. Given the well-known antimicrobial properties of eugenol, ${ }^{37}$ as well as its successful incorporation in antimicrobial polymeric systems, ${ }^{38}$ the antimicrobial activity of the thermoset was investigated. Antimicrobial activity against E. coli was tested, following the protocol reported in the Experimental Section. However, no significant inhibition was registered. The reason behind the loss of activity of eugenol once incorporated in the thermoset structure can be found in the loss of the allyl moiety after the cross-linking reaction. The allyl group is necessary for the interaction with microorganisms, ${ }^{39}$ therefore its reaction inhibits its action.

\section{CONCLUSIONS}

The synthesis and characterization of innovative high-performance thermoset starting from renewable feedstocks was successfully demonstrated. Taking advantage of the emerging DOX polymerization chemistry, a tailored monomer functionalized by naturally occurring phenol, eugenol, was successfully synthesized. The monomer was further polymerized and cured in one-pot through the simultaneous polymerization of DOX and reaction through eugenol double bonds leading to crosslinked structure. The thermoset obtained proved to possess outstanding mechanical properties and good thermal stability. Microwave-assisted hydrothermal degradation in alkaline water or methanol completely degraded the thermoset to water or methanol soluble low molecular weight products, showing recyclability back to functional intermediates. Structural investigation of the degradation products allowed envisioning the chemical structure of the thermoset indicating polylactidelike chains cross-linked with aromatic-aliphatic segments formed by reaction of the eugenol double bonds. The presence of free hydroxyl and carboxyl groups gives a plausible explanation to the disclosed shape memory and self-healing properties of the thermoset through transesterification.

\section{ASSOCIATED CONTENT}

\section{S Supporting Information}

The Supporting Information is available free of charge on the ACS Publications website at DOI: 10.1021/acssuschemeng.8b03655.

${ }^{1} \mathrm{H}$ and ${ }^{13} \mathrm{C}$ NMR spectra of the synthesized compounds and DSC thermogram for the thermoset (PDF)

\section{AUTHOR INFORMATION}

\section{Corresponding Author}

*E-mail: minna@kth.se.

ORCID

Minna Hakkarainen: 0000-0002-7790-8987

Alessandra Silvani: 0000-0002-0397-2636

Notes

The authors declare no competing financial interest.

\section{REFERENCES}

(1) Dumas, L.; Bonnaud, L.; Olivier, M.; Poorteman, M.; Dubois, P. Chavicol benzoxazine: Ultrahigh $\mathrm{T}_{\mathrm{g}}$ biobased thermoset with tunable extended network. Eur. Polym. J. 2016, 81, 337-346.

(2) Patil, N. V.; Netravali, A. N. Nonedible Starch Based "Green" Thermoset Resin Obtained via Esterification Using a Green Catalyst. ACS Sustainable Chem. Eng. 2016, 4, 1756-1764.

(3) Wang, Z.; Yuan, L.; Ganewatta, M. S.; Lamm, M. E.; Rahman, M. A.; Wang, J.; Liu, S.; Tang, C. Plant Oil-Derived Epoxy Polymers toward Sustainable Biobased Thermosets. Macromol. Rapid Commun. 2017, 38, 1700009.

(4) Jahandideh, A.; Muthukumarappan, K. Synthesis, characterization and curing optimization of a biobased thermosetting resin from xylitol and lactic acid. Eur. Polym. J. 2016, 83, 344-358.

(5) Xu, Y.; Hua, G.; Hakkarainen, M.; Odelius, K. Isosorbide as Core Component for Tailoring Biobased Unsaturated Polyester Thermosets for a Wide Structure-Property Window. Biomacromolecules 2018, 19, 3077-3085.

(6) Barrett, D. G.; Merkel, T. J.; Luft, J. C.; Yousaf, M. N. One-Step Syntheses of Photocurable Polyesters Based on a Renewable Resource. Macromolecules 2010, 43, 9660-9667.

(7) Ma, S.; Webster, D. C. Degradable thermosets based on labile bonds or linkages: A review. Prog. Polym. Sci. 2018, 76, 65-110.

(8) Buchwalter, S. L.; Kosbar, L. L. Cleavable epoxy resins: design for disassembly of a thermoset. J. Polym. Sci., Part A: Polym. Chem. 1996, 34, 249-260.

(9) Harada, M.; Ando, J.; Yamaki, M.; Ochi, M. Synthesis, characterization, and mechanical properties of a novel terphenyl liquid crystalline epoxy resin. J. Appl. Polym. Sci. 2015, 132, 41296.

(10) Torpanyacharn, O.; Sukpuang, P.; Petchsuk, A.; Opaprakasit, P.; Opaprakasit, M. Curable precursors derived from chemical recycling of poly(ethylene terephthalate) and polylactic acid and physical properties of their thermosetting (co)polyesters. Polym. Bull. 2018, 75, 395-414.

(11) Sakai, R.; John, B.; Okamoto, M.; Seppala, J. V.; Vaithilingam, J.; Hussein, H.; Goodridge, R. Fabrication of Polylactide-Based Biodegradable Thermoset Scaffolds for Tissue Engineering Applications. Macromol. Mater. Eng. 2013, 298, 45-52.

(12) Zenkiewicz, M.; Malinowski, R.; Rytlewski, P.; Richert, A.; Sikorska, W.; Krasowska, K. Some composting and biodegradation effects of physically or chemically crosslinked poly(lactic acid). Polym. Test. 2012, 31, 83-92.

(13) Tounthai, J.; Petchsuk, A.; Opaprakasit, P.; Opaprakasit, M. Curable polyester precursors from polylactic acid glycolyzed products. Polym. Bull. 2013, 70, 2223-2238.

(14) Datta, R.; Henry, M. Lactic acid: recent advances in products, processes and technologies - a review. J. Chem. Technol. Biotechnol. 2006, 81, 1119-1129.

(15) Albertsson, A. C.; Hakkarainen, M. Designed to degrade. Science 2017, 358 (6365), 872-873.

(16) Jahandideh, A.; Muthukumarappan, K. Star-shaped lactic acid based systems and their thermosetting resins; synthesis, characterization, potential opportunities and drawbacks. Eur. Polym. J. 2017, 87, 360-379.

(17) Chang, S.; Zeng, C.; Li, J.; Ren, J. Synthesis of polylactidebased thermoset resin and its curing kinetics. Polym. Int. 2012, 61, $1492-1502$. 
(18) Helminen, A.; Korhonen, H.; Seppala, J. V. Biodegradable crosslinked polymers based on triethoxysilane terminated polylactide oligomers. Polymer 2001, 42, 3345-3353.

(19) Meekum, U.; Kingchang, P. Peroxide/Silane Crosslinked Poly(lactic acid) Hybrid Biocomposite Reinforced with Empty Fruit Bunch and Cotton Fibers for Hot-Fill Food Packaging. BioResources 2017, 12 (3), 5086-5101.

(20) Thillaye du Boullay, O.; Marchal, E.; Martin-Vaca, B.; Cossio, F. P.; Bourissou, D. An Activated Equivalent of Lactide toward Organocatalytic Ring-Opening Polymerization. J. Am. Chem. Soc. 2006, 128, 16442-16443.

(21) Martin Vaca, B.; Bourissou, D. O-Carboxyanhydrides: Useful Tools for the Preparation of Well- Defined Functionalized Polyesters. ACS Macro Lett. 2015, 4, 792-798.

(22) Cairns, S. A.; Schultheiss, A.; Shaver, M. P. A broad scope of aliphatic polyesters prepared by elimination of small molecules from sustainable 1,3-dioxolan-4-ones. Polym. Chem. 2017, 8, 2990-2996.

(23) Martin, R. T.; Camargo, L. P.; Miller, S. A. Marine-degradable polylactic acid. Green Chem. 2014, 16, 1768-1773.

(24) Almaroof, A.; Niazi, S. A.; Rojo, L.; Mannocci, F.; Deb, S. Influence of a polymerizable eugenol derivative on the antibacterial activity and wettability of a resin composite for intracanal post cementation and core build-up restoration. Dent. Mater. 2016, 32, 929-939.

(25) Kaufman, T. S. The Multiple Faces of Eugenol. A Versatile Starting Material and Building Block for Organic and Bio-Organic Synthesis and a Convenient Precursor Toward Bio-Based Fine Chemicals. J. Braz. Chem. Soc. 2015, 26 (6), 1055-1085.

(26) Liu, T.; Hao, C.; Wang, L.; Li, Y.; Liu, W.; Xin, J.; Zhang, J. Eugenol-Derived Biobased Epoxy: Shape Memory, Repairing, and Recyclability. Macromolecules 2017, 50, 8588-8597.

(27) Zhang, Y.; Li, Y.; Thakur, V. K.; Gao, Z.; Gu, J.; Kessler, M. R. High-performance thermosets with tailored properties derived from methacrylated eugenol and epoxy-based vinyl ester. Polym. Int. 2018, 67, 544-549.

(28) Faye, I.; Decostanzi, M.; Ecochard, Y.; Caillol, S. Eugenol biobased epoxy thermosets: from cloves to applied materials. Green Chem. 2017, 19, 5236-5242.

(29) Zhang, X.; Dai, Y. A Functionalized Cyclic Lactide Monomer for Synthesis of Water-Soluble Poly(Lactic Acid) and Amphiphilic Diblock Poly(Lactic Acid). Macromol. Rapid Commun. 2017, 38, 1600593.

(30) Bredikhina, Z. A.; Pashagin, A. V.; Kurenkov, A. V.; Bredikhin, A. A. Synthesis of Enantiomerically Pure 3-Aryloxy-2-hydroxypropanoic Acids, Intermediate Products in the Synthesis of cis-4Aminochroman-3-ols. Russ. J. Org. Chem. 2014, 50, 535-539.

(31) Yang, X.; Odelius, K.; Hakkarainen, M. Microwave-Assisted Reaction in Green Solvents Recycles PHB to Functional Chemicals. ACS Sustainable Chem. Eng. 2014, 2, 2198-2203.

(32) Zhao, S.; Huang, X.; Whelton, A. J.; Abu-Omar, M. M. Renewable Epoxy Thermosets from Fully Lignin-Derived Triphenols. ACS Sustainable Chem. Eng. 2018, 6 (6), 7600-7608.

(33) McMaster, M. S.; Yilmaz, T. E.; Patel, A.; Maiorana, A.; ManasZloczower, I.; Gross, R.; Singer, K. D. Dielectric Properties of BioBased Diphenolate Ester Epoxies. ACS Appl. Mater. Interfaces 2018, 10, 13924-13930.

(34) Ma, Z.; Liao, B.; Wang, K.; Dai, Y.; Huang, J.; Pang, H. Synthesis, curing kinetics, mechanical and thermal properties of novel cardanol-based curing agents with thiourea. RSC Adv. 2016, 6, 105744.

(35) Berg, G. J.; McBride, M. K.; Wang, C.; Bowman, C. N. New directions in the chemistry of shape memory polymers. Polymer 2014, $55,5849-5872$.

(36) Montarnal, D.; Capelot, M.; Tournilhac, F.; Leibler, L. SilicaLike Malleable Materials from Permanent Organic Networks. Science 2011, 334 (6058), 965-968.

(37) Phanthong, P.; Lomarat, P.; Traidej Chomnawang, M.; Bunyapraphatsara, N. Antibacterial activity of essential oils and their active components from Thai spices against foodborne pathogens. ScienceAsia 2013, 39, 472-476.

(38) Rojo, L.; Vàzquez, B.; San Romàn, J.; Deb, S. Dent. Mater. 2008, 24, 1709-1716.

(39) Hu, Q.; Zhou, M.; Wei, S. J. Food Sci. 2018, 83 (6), 14761483. 